\title{
OBSERVAÇÕES SOBRE AS MUDANÇAS NO ENSINO MÉDIO DO BRASIL
}

Cristiano Amaral Garboggini Di Giorgi, Fernanda Siquini Valenciano

Universidade do Oeste Paulista - UNOESTE, Programa de Pós-Graduação em Educação, Presidente Prudente, SP. Email: utopico92@gmail.com, sqnandavalenciano@outlook.com

\section{RESUMO}

Este artigo observa a Lei no 9.934/96, que rege a Educação brasileira, especificamente o Ensino Médio e as mudanças previstas pela Lei no 13.415/17, com a necessidade de mudar a Educação no Brasil, na qual revela uma flexibilização do ensino. O objetivo desse estudo foi de buscar informações sobre as mudanças e como as ações comunicativas se dão nos espaços escolares. A metodologia se fez por leitura bibliográfica e análise das propostas de mudanças previstas pela lei. Pelos resultados, observa-se que as mudanças são necessárias, mas as estruturas pessoais e de formação docente não compreendem o objetivo real, portanto, concluímos que num sistema capitalista a busca pelas mudanças nos espaços escolares não foi discutida, o que assume um caráter de interesse político social e econômico.

Palavras-chave: Educação. Sujeitos. Políticas Educacionais e Reformas.

\section{OBSERVATIONS ON THE CHANGES IN THE BRAZILIAN HIGH SCHOOL}

\begin{abstract}
This article observes Law No. 9.934 / 96, which governs Brazilian Education, specifically the High School and the changes provided for in Law No. 13.415 / 17, with the need to change Education in Brazil, in which it reveals a more flexible teaching. The purpose of this study was to seek information about changes and how communicative actions take place in school spaces. The methodology was done by bibliographical reading and analysis of proposed changes provided by law. From the results, it is observed that changes are necessary, but personal structures and teacher training do not understand the real objective, therefore, we conclude that in a capitalist system the search for changes in school spaces was not discussed, which assumes a character of political and social interest.
\end{abstract}

Keywords: Education. Subjects. Educational Policies and Reforms. 


\section{INTRODUÇÃO}

O cenário educacional revela um descaso, com os sujeitos do processo de ensino e aprendizagem. As preocupações são pautadas na necessidade de melhorar a educação, mas como se observa, tal melhoria está objetivada nos resultados expressos pelas avaliações em escala nacional e estadual. Ao contrário desta observação, as políticas educacionais não afirmam isso com tal clareza, mas suas ações são objetivadas num ensino que visa a inserção do sujeito no mercado de trabalho, e em nenhum momento tem como objetivo a inserção deste num mundo melhor, onde a desigualdade se dissipa pela sua capacidade e habilidade intelectual. Desde o século XIX a Educação tem sido voltada para os interesses capitalistas, "a boa qualificação tornou-se monopólio das classes dominantes. A educação ao privilegiar os mais dotados de capital cultural, beneficia as crianças das classes sociais mais favorecidas" (SOUZA, 2016), e não é diferente atualmente, aliás é mais real e nítido que antes, frente a um governo que julga ser melhor para uma nação que sua educação seja regida por outros, é a privatização do ensino em pauta.

A luta de classes observada pela educação acontece não apenas entre classes sociais, mas dentro da própria classe, dentro de uma mesma categoria: são alunos com alunos, professores com professores, escolas com escolas, etc, e o que acentua tal luta, nem chega a ser em grande preocupação apenas a desigualdade social entres esses sujeitos, mas as avaliações de larga escala que colocam em disputa uma vaga na universidade, uma bolsa de estudo, um mérito financeiro ao professor e sua escola. Contudo, o governo acirra essa luta quando julga ser necessária uma mudança na educação que torna a desigualdade ainda maior.

Para Souza (2016), o capital econômico e o capital cultural são as formas de capital mais importante para estruturar 0 espaço social, umas vez que fornecem os principais critérios de diferenciação simbólica, para tanto o espaço social dever ser, no mínimo, socializador, um local cuja desigualdade desapareça para que as formas de convivência sejam mutuamente crescentes para os sujeitos inseridos nela, esta simbologia está ligada exatamente às formas como as pessoas agem e como seus habitus interferem no desenvolvimento humano, intelectual e estruturante do sujeito. As estruturas cognitivas e sociais são necessárias para que não haja, inclusive, uma violência simbólica, onde o saber mais ou saber menos não ganhem espaço, mas a troca de saberes seja pautada num comportamento de interesse no outro e não no interesse capital individual.

É notável numa nação em que o cargo que se ocupa num determinado emprego, a posição que se ocupa na sociedade, os locais que se frequentam e os grupos de amigos determinam, de certa forma, o habitus cultural do sujeito; e devido às grandes exigências de mercado, de sociabilidade e de mundo, as pessoas buscam mais ainda títulos e ascensão social, assim acumular capital cultural e simbólico é prestígio e distinção social, contudo, desigualdade. Neste sentido, um governo que busca acirrar as lutas de classes não pensa numa nação promissora e unificada, mas no assentamento da ascensão à desigualdade social, que visa tornar o capitalismo predominantemente acima dos interesses públicos.

O objetivo desse estudo, foi de mostrar que a Educação deveria, todavia, ser universal e inclusiva, porém, num cenário de competição e disputa por vagas, por méritos, por notas, há de se pensar que as reformas são necessárias e urgentes, mas não com o objetivo de acentuar tais lutas, mas de preconizar o desenvolvimento pleno do indivíduo, justamente para que este seja preparado para um mundo em que se configura: lutas e disputas, afinal 'a escola mudou radicalmente porque mudou a população que a frequenta, tornou-se local de encontro de todos os setores da sociedade e campo de repercussão de todas 
as tensões que conturbam a vida coletiva moderna'. (DI GIORGI; LEITE, 2010, p. 315), assim, as configurações que tangem 0 cenário educacional devem acompanhar essa modernidade num discurso também coletivo.

\section{METODOLOGIA}

Através da leitura bibliográfica e análise das propostas previstas na Lei no $13.415 / 17$, nota-se que por trás desta, de uma escola, de uma classe com alunos e professores, de gestores e todo este cenário, há acima de tudo, uma constituição de sujeitos que estão inseridos na Educação, que segundo Singer (1995, p. 5) está dividida e polarizada em duas visões opostas dos fins da educação e de como atingi-los, pois, o grande propósito da educação seria proporcionar ao filho das classes trabalhadoras a consciência, portanto, a motivação, em que se constrói uma sociedade mais livre e igualitária.

No entanto, a Medida Provisória 764/16, onde a discussão é ignorada pelos poderes públicos, fica em contrapartida desta educação em que a 'sociedade seja mais livre e igualitária'. A proposta contraria a própria lei que define em que a educação seja universal, inclusiva e para todos, pois a partir do momento em que se toma medidas que envolve uma nação e não se discute os direitos, os deveres e os desejos dos sujeitos, esta torna-se escrava num tempo de liberdade e democracia que é omitida por um governo capitalista.

As duas visões de que Singer aborda (1995, p.5), trata de uma visão civil democrática, cujo objetivo está pautado numa pedagogia que traz a igualdade de oportunidade para todos, visando uma formação cidadã, contudo para aqueles que têm menos oportunidade, pois preocuparase com a autonomia do educando, sendo uma formação global e integral do indivíduo. Já numa segunda visão abordada por ele traz a inserção econômica do indivíduo, busca o bem-estar social, o crescimento e o desenvolvimento profissional, nomeia esta de produtivista, pois gera o 'capital humano'.
Porém, Singer (1995, p. 6) afirma que as duas visões valorizam a educação como meio de melhorar a sociedade, [...] mas as concepções de como a sociedade e a economia funcionam, que subjazem a cada visão, são muito diversas e se integram em legados ideológicos opostos. Por isso, podese pontuar que uma está voltada para o eu enquanto a outra está para o todo, uma individualista, outra universal. Analisando tais visões, chega-se à ideia de que onde se busca a formação do sujeito de modo global e integral, busca-se ali a mudança social, a tomada de consciência para o desenvolvimento do todo, do universo, todavia, onde se busca a formação do desenvolvimento profissional busca-se a individualidade, o crescimento de eu, do olhar para si e preocupar-se consigo e depois com o todo.

As visões democrática civil e produtivista em sua oposição geram uma visão de desigualdade social, pois nota-se que as propostas de mudança para a educação, especificamente para o Ensino Médio do Brasil, tem essa visão produtivista, em que 'a rede escolar esteja sujeita às regras do mercado, de modo que os diretores e os professores tenham interesse em formar ganhadores' (SINGER, 1995, p.8), são avaliações de larga escala que buscam resultados acima de resultados, e julgam escolas e professores por classificação de alunos e inserção em universidades, como também apontam Di Giorgi e Leite (2004, p.137) que 'o professor tem sido cobrado e responsabilizado pelas fragilidades do sistema educacional, sem que as escolas estejam providas de recursos materiais, de equipamentos, de condições de trabalho e de profissionais que auxiliem $o$ trabalho docente'.

Entretanto, o que se observa na análise dos resultados toma como base para tal proposta de que a Educação deve servir ao mercado, produzir sujeitos que saibam produzir, um paradoxo da própria Educação, um ato de olhar o produto e não o sujeito, o resultado e não processo, pois a crise no 
sistema escolar existe, e não é recente os estudos e preocupações acerca do assunto, contudo, a estrutura política e social do país emergem para isso, pois a escola fragilizada pelas ações políticas perde a força de educar e socializar os sujeitos da aprendizagem para as lutas do mundo, muitos são os motivos para que se permaneça em tal cenário: o excesso de professores formados, a má formação e preparação destes para a realidade da escola pública, a desvalorização da carreira docente, o baixo salário, a privatização do ensino, entre outros aspectos que torna o docente refém de uma educação precária.

\section{RESULTADOS}

Acredita-se que o professor seja
autônomo por suas competências e habilidades em suas atitudes dentro da sala de aula, mas falar em autonomia só da sala de aula é desvalorizar a categorização docente, pois há de se considerar que antes de tudo deve haver um valor humano, onde seres buscam melhorias profissionais e pessoais, 'da autonomia como chave para compreensão de um problema específico do trabalho educativo, características que se mostrará essencial na possibilidade de desenvolvimento das qualidades essenciais para a prática educativa' (CONTRERAS, 2002, p.89).

Pensar a escola sem reflexão é impossível, pois esta é um lugar de pessoas e feita para pessoas, para construção de pessoas, evolução de pessoas. Se a crise na Educação existe é um problema de todos e não se pode permitir que reformas educacionais aconteçam sem que haja discussões com os envolvidos do processo, 'o espaço para o avanço educacional depende essencialmente de uma radicalização da democracia da criação de espaços de debate público no interior da sociedade civil com poder decisório, do crescimento da "ação comunicativa"' (HABERMAS, 1987 apud DI GIORGI; LEITE, 2010, p. 322), assim, refletir sobre os espaços escolares e dentro destes é mais que necessário, é primordial. Como afirma Esteve (1999, p. 102), sobre as mudanças, de que 'o momento atual exige que o professor explicite os seus valores e objetivos educativos", pois as práticas do professor não são apenas em torno de suas competências e habilidades, dos conteúdos, ou de uma base a ser cumprida, mas estas refletem seu modo de vida, sua filosofia de pensamento, suas práticas sociais que ultrapassam os muros da escola e interferem na formação pessoal de seus alunos, como aborda Contreras (2002, p.103) que

'em uma sala de aula
acontecem muito mais
coisas do que se poderia
prever e manipular em um
esquema de relação entre
ações educativas e efeitos
pretendidos. E a maior
parte delas exige uma
situação docente, seja em
relação à sua utilização
educativa, seja para
reconduzir o sentido ou
reduzir os seus efeitos'.

Deste modo, não há uma técnica para se pôr em prática ações diante das imprevisões dos acontecimentos, bem como colocar uma proposta de mudança onde uma parte das aulas seja ofertada em módulo à distância; é retirar do aluno o direito de trocar experiências e enriquecer suas atitudes pela vivência com o outro, seja professor, aluno ou outro agente da escola, é acima de tudo, retirar da categoria docente a arte de se comunicar e se fazer comunicação para desenvolvimento pessoal e intelectual.

\section{DISCUSSÃO}

A educação por si só não faz mudanças, nenhum sistema de ensino por sua própria estrutura faz mudanças, a educação deve acima de tudo, assegurar uma formação científica e cultural para a vida pessoal, profissional e cidadã, para que os sujeitos do processo sejam autônomos em suas relações, assim, o professor deve mediar as relações em suas práticas pedagógicas, ser o mediador do processo, atuando no favorecimento da aprendizagem universal. 
Aplicar conteúdos, qualquer ser de notório saber aplicaria, mas incutir valores inerentes ao indivíduo, a uma turma, compreender a necessidade de discutir assuntos relevantes para um determinado momento, mesmo que estes estejam 'fora' do planejamento didático, só o professor, que atua como mediador, como ser humano desenvolvedor de culturas e aprendizagens é que pode ser capaz de tal prática. Aspirar ao ensino como ele sendo educativo e transformador, necessita-se de docentes transformadores e capacitados, 'a relação entre as qualidades das atuações profissionais e as exigências da prática docente reflete também a dialética entre, por um lado, condições e restrições da realidade educativa, e, por outro, formas de viver e desenvolver a profissão enquanto atitudes e destrezas postas em jogo pelos membros concretos da profissão'. (CONTRERAS, 2002, p.83).

Contudo, a escola que não toma uma atitude, uma posição, extermina a profissionalidade docente no que se refere às práticas educativas e transformadoras, impedindo, portanto, o professor de contribuir para a formação social do indivíduo, haja vista, pensando que ele pode ser fonte de referência e influências nas práticas dos alunos como cidadãos fora do contexto escolar. Todavia, nesse contexto de mudanças, reformas, propostas e transformações, preocupa-se e fala-se tanto no bem-estar do aluno, mas não se envolvem com seus contextos e suas implicações, por isso, ser o professor ético e profissional permite que relações afetivas existem na escola para criar um espaço de respeito e compromisso com a moral, é, portanto, colocar à priori a formação de caráter dos alunos.

A responsabilidade sobre a educação e com a Educação envolve uma comunidade participativa, contudo, 'o problema surge pelo fato de que, por outro lado, o professor só pode assumir seu compromisso moral a partir da autonomia, não da obediência, porque não é possível resolver conflitos e dilemas senão partir da autonomia dos mesmos' (CONTRERAS, 2002). Para Diniz-Pereira (2017, p.11) 'tal processo deve ser dar concomitantemente à denúncia e à resistência aos processos brutais de precarização, intensificação e aumento de controle sobre o trabalho docente, de diminuição da autonomia profissional, de aviltamento salarial dos professores e de desqualificação profissional'; eis aí uma sugestão de melhoria do ensino, da escola pública e da valorização da categoria docente e do aluno em seu processo de aprendizagem e desenvolvimento pessoal e intelectual, pois isto seria dar significado à prática docente, equalizar os indivíduos de modo que sua formação pessoal e social esteja ligada à autonomia no combate às desigualdades e injustiças sociais, porém, o sistema capitalista não converge para tal prática, aliás, está em desacordo com toda ideologia que busca discussão das políticas educacionais e sociais. Pode-se concluir o exposto acima no pensamento de Contreras (2002, p. 81) em que 'a educação requer responsabilidade e não se pode ser responsável se não se é capaz de decidir, seja por impedimentos legais ou por falta de capacidades intelectuais morais'.

\section{CONCLUSÃO}

Da precariedade à necessidade na Educação é olhar num panorama histórico do século XIX ao século XXI e observar que a escola se configura do mesmo modo, todavia, isso pode ser modificado dentro de uma estrutura do século XIX com professores de autonomia em suas práticas pedagógicas que devem ser inovadoras e buscar o olhar sobre o aluno em primeiro lugar. Porém, o que não muda não é parte humana, mas a estrutura de um sistema capitalista que governa a Educação, e cujos olhares estão voltados para manutenção do mercado de trabalho, que obviamente tem uma visão empresarial e não educativa. Preparar alunos para uma ascensão profissional e manter a hierarquia do sistema político e social do país, é propor ao aluno que ele não busque avanços a longo 
prazo, mas que se 'encaixe' numa estrutura de oferta de emprego, pois o trabalho pode ser provisório, é prepara-lo para o hoje, para suprir as necessidades dos maiores na sustentação da ideia de classes que gera uma desigualdade confortável aos indivíduos das classes mais abastadas. Num contexto onde os filhos das classes menos abastadas têm um ambiente menos propício para os estudos se comparado ao ambiente de filhos de classes mais abastadas, 'a escola pública não se adaptou nem pretende se adaptar à nova realidade de que agora ela está oferecendo um serviço universal, ou seja, para todos. Ela continua preparando uma minoria e naturalmente expulsa como corpo estranho os descendentes da maioria não escolarizada' (SINGER, 1995, p.13). Para tanto, enquanto houver uma escola que não reflete suas ações e sobre suas ações, o sistema que rege a sociedade como um todo continuará ditando ordens, e mudanças, e reformas e transformações que subsidiem suas necessidades. Como também afirma Alarcão (2001, p.26) sobre a postura da escola, em que

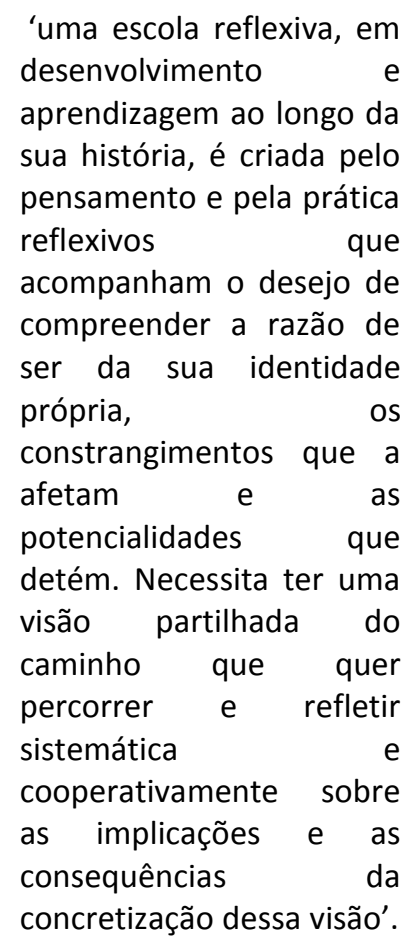

Deste modo, como pode uma escola ser aberta se se fecha a um modelo integral que oferece, mas que não oportuniza espaço para a socialização. Como já foi abordado, a escola é formada por pessoas e para pessoas, portanto, um 'organismo vivo', difícil, então, compreender que como ela sendo um organismo vivo não pensa no seu núcleo, o ser humano, exatamente a mão-de-obra que busca o sistema capitalista para suprir as necessidades de mercado. Diante da atual situação, nota-se que a escola ser ausente é necessário para o crescimento do sistema e fortalecimento deste, pois ao analisar a escola como um 'espaço socializador' observa-se que ela vai se configurando numa fábrica de robôs, ou mesmo de pessoas moldadas, como num serviço terceirizado onde se pensa que a flexibilidade de escolha imposta é a própria autonomia do ser, contudo, 'não é na consciência dos homens que determina o seu ser, mas, ao contrário, é o seu ser social que determina sua consciência. [...] com a transformação da base econômica, toda a enorme superestrutura se transforma com maior ou menor rapidez'. (MARX, 1982, p.25 apud NETTO, 2011, p.51).

Considerando a dualidade de uma sociedade civil democrática e uma produtivista, a luta de classes por interesses e a própria luta dentro das classes; considerando ainda a autonomia utópica do professor e a incapacidade de reflexão da escola enquanto espaço socializador para pessoas e de formação de pessoas, observase que onde não há ação comunicativa, há imposição de um sistema capitalista sobre uma sociedade de olhos vendados frente às mudanças que convergem para uma maior desigualdade social.

\section{REFERÊNCIAS}

ALARCÃO, Isabel. Escola Reflexiva e Nova

Racionalidade.Porto Alegre: Artmed Editora, 2001.

\section{CONTRERAS, José. A autonomia de}

professores. São Paulo: Cortez, 2002.

DI GIORGI, Cristiani Amaral Garborggini.

LEITE, Yoshie Ussami Ferrari. A qualidade da escola pública, na perspectiva democrática e 
popular. Série-Estudos, Campo Grande, v.30, p. 305-323, Jul./Dez. 2010. Disponível em:

<http://www.serie-

estudos.ucdb.br/index.php/serie-

estudos/article/view/173>. Acesso em 13

jun., 2018.

DI GIORGI, Cristiano Amaral Garborggini.

LEITE, Yoshie Ussami Ferrari. Saberes

docentes de um novo tipo na formação

profissional do professor: alguns

apontamentos. Educação, Santa Maria, v.29, n.2, p.135 - 145, Jul. /Dez. 2004. Disponível

em:

<https://periodicos.ufsm.br/reveducacao/art icle/view/3846>. Acesso em 13 jun., 2018.

DINIZ-PEREIRA, Júlio Emílio. Olhar o magistério "no próprio espelho": O conceito de profissionalidade e as possibilidades de se repensar o sentido da profissão docente.

Revista Portuguesa de Educação, Braga, v.30, n.1, p.7-34, 2017. Disponível em: <http://revistas.rcaap.pt/rpe/article/view/10 72>. Acesso em: 13 jun., 2018.

ESTEVE, José M. Mudanças Sociais e função docente: capítulo IV. Organização de António Nóvoa. Porto: Porto Editora Ltda, 1999.

(Profissão Professor)

NETTO, José Paulo. Introdução ao estudo do Método Marx. São Paulo: Expressão Popular Editora, 2011.

SOUZA, Michel Aires de. Pierre Bourdieu: educação trabalho e a manutenção da ordem social. 02 jan. 2016. Disponível em: <https://filosofonet.wordpress.com/2016/01 /02/pierre-bourdieu-educacao-trabalho-e-amanutencao-da-ordem-social/>. Acesso em: 03 jun., 2018.

SINGER, Paul. Poder, política e educação.

Revista Brasileira de Educação, n.1, p.6-15, Jan./Fev./Mar./Abr., 1996. Disponível em: <http://www.ia.ufrrj.br/ppgea/conteudo/T21SF/Sandra/Poder,\%20pol\%EDtica\%20e\%20e
duca\%E7\%E3o.pdf>. Acesso em: 20 jun., 2018. 